\title{
The effect of lactulose, pectin, arabinogalactan and cellulose on the production of organic acids and metabolism of ammonia by intestinal bacteria in a faecal incubation system
}

\author{
BY A. J. VINCE, N. I. MCNEIL, J. D. WAGER AND O. M. WRONG* \\ Department of Medicine, The Rayne Institute, University College and Middlesex School of \\ Medicine, University Street, London WCIE 6JJ
}

(Received 7 June 1989-Accepted 28 August 1989)

\begin{abstract}
An in vitro faecal incubation system was used to study the metabolism of complex carbohydrates by intestinal bacteria. Homogenates of human faeces were incubated anaerobically with added lactulose, pectin, the hemicellulose arabinogalactan, and cellulose, both before and after subjects had been pre-fed each carbohydrate. Fermentation of added substrate was assessed by the production of short-chain fatty acids (SCFA) and suppression of net ammonia generation over $48 \mathrm{~h}$ of incubation. Control faecal homogenates to which carbohydrate was not added yielded an average increment of SCFA of $43 \mathrm{mmol} / \mathrm{l}$, equivalent to $172 \mathrm{mmol} / \mathrm{kg}$ in the original stool. The addition of lactulose, pectin and arabinogalactan each increased the yield of SCFA by a similar amount, averaging $6.5 \mathrm{mmol} / \mathrm{g}$ carbohydrate or $1.05 \mathrm{~mol} / \mathrm{mol}$ hexose equivalent; organic acid yield was not increased by pre-feeding these substances for up to 2 weeks. Acetate was the major SCFA in all samples at all times and, after pre-feeding with extra carbohydrate, butyrate concentrations exceeded propionate in all samples. Faecal homogenates incubated with cellulose showed no greater SCFA production than controls over the first $48 \mathrm{~h}$, but there was a slight increase when samples from two subjects pre-fed cellulose were incubated for $14 \mathrm{~d}$. Net ammonia generation was markedly suppressed by addition of lactulose to faecal incubates with an initial period of net bacterial uptake of ammonia. Pectin and arabinogalactan also decreased ammonia generation, but the reductions were not significant unless subjects were pre-fed these materials; cellulose had no effect on ammonia generation.
\end{abstract}

Ammonia: Carbohydrates: Faecal incubation: Short-chain fatty acids

Dietary plant fibre influences many aspects of intestinal function, but in the intact organism it may be difficult to distinguish the purely physical effects of fibre transit through the bowel from the metabolic effects that follow its breakdown by intestinal bacteria. In this laboratory we have developed an in vitro method of stool incubation which can be used to study the metabolic activity of intestinal bacteria (Vince et al. 1976; Chadwick et al. 1978). In this system the disaccharide lactulose is metabolized with the production of large amounts of short-chain fatty acids (SCFA) and a marked decrease in bacterial formation of ammonia (Vince et al. 1978). These processes have both nutritional and therapeutic implications for the host, for SCFA are absorbed rapidly through the colonic mucosa (McNeil et al. 1978), and a decrease in the production and hence the absorption of ammonia is probably the major factor in the effect of lactulose in lowering the blood ammonia concentration of patients with porto-systemic encephalopathy (Weber, 1981; Crossley \& Williams, 1984). Similar effects might be expected from the carbohydrates of plant fibre, which are known to be digested to varying degrees by the large-bowel flora (Cummings, 1981 a).

* For reprints. 
The aim of the present study was to compare the influence of four carbohydrates lactulose, pectin, a hemicellulose (arabinogalactan) and cellulose - on the production of SCFA and ammonia in our faecal incubation system. To determine whether previous exposure to increased amounts of these carbohydrates significantly alters bacterial metabolism in the gut, faecal samples were obtained from subjects before and after they had ingested more than twice the normal dietary amounts of each substance.

\section{METHODS \\ Subjects and dietary protocol}

Five healthy subjects aged $27-56$ years and weighing $44-83 \mathrm{~kg}$ were studied, first while taking their usual diets and later while eating their usual diets with the addition of various carbohydrates-lactulose (Duphar), pectin (H. P. Bulmer Ltd), arabinogalactan (gum acacia; L. J. Richards \& Co. Ltd), and cellulose (Whatman). Carbohydrates were taken in the order chosen by the subject, with a minimum period of 1 month between ingestion of each. Pectin and cellulose, which are bulky and difficult to ingest in large amounts, were taken in a dose of $0.3 \mathrm{~g} / \mathrm{kg}$ per d; pectin as a powder in gelatin capsules, cellulose suspended in fruit squash. Lactulose and arabinogalactan were taken in a dose of $0.8 \mathrm{~g} / \mathrm{kg}$ per d; lactulose as Duphalac syrup, arabinogalactan in fruit squash. These doses represent more than twice the amount of each carbohydrate likely to be present in a normal diet (Bingham et al. 1979). Dietary additions were taken in three or four doses daily. Side effects were minimal, consisting of wind and, particularly with cellulose, a sensation of fullness.

Two subjects consumed their extra dietary carbohydrates for $14 \mathrm{~d}$, faeces being studied after 2, 7 and $14 \mathrm{~d}$. Because the observed effects on SCFA production and ammonia metabolism were no greater after 7 and $14 \mathrm{~d}$ than after $2 \mathrm{~d}$ (see Results), the remaining subjects were studied only after $2 \mathrm{~d}$.

\section{Collection and processing of faecal samples}

Faeces were passed into plastic bags and immediately homogenized with three times their weight of physiological saline $(9 \mathrm{~g}$ sodium chloride/l) under a stream of oxygen-free nitrogen. Faecal incubations (Vince et al. 1976) were then made as follows:

Normal diet without extra carbohydrate. Five equal $40-100 \mathrm{ml}$ portions of faecal homogenate were dispensed into incubation vessels. One portion served as control, the other four were supplemented with either lactulose, pectin, arabinogalactan or cellulose to a final concentration of $10 \mathrm{~g} / 1$. The sources of the carbohydrate supplement were the same as those used for dietary supplements except that a chemically pure preparation of lactulose, supplied by Phillips-Duphar of Amsterdam, was used instead of Duphalac syrup. All five portions were incubated simultaneously under $\mathrm{N}_{2}$ for $48 \mathrm{~h}$ at $37^{\circ}$ with the $\mathrm{pH}$ maintained at or above $\mathrm{pH} 5.5$ by automatic titration with $3 \mathrm{~mol}$ sodium hydroxide/1; the $\mathrm{pH}$ was prevented from falling below 5.5 because a more acid reaction has been shown to inhibit the metabolism of intestinal bacteria (Vince et al. 1973; Vince \& Burridge, 1980). Portions were removed for analysis of ammonia and osmolality at $0,1 \cdot 5,3,6,24$ and $48 \mathrm{~h}$, and at 0 and $48 \mathrm{~h}$ samples were also taken for analysis of total and individual organic anions, total $\mathrm{N}$, and bacterial counts. (Ammonia was measured more frequently than other variables because previous experiments showed an initial fall before a rise in concentration, whereas the other variables changed steadily in the same direction (Vince et al. 1978).)

Diets containing extra carbohydrate. The procedure was identical to that described by Vince et al. (1976) except that only two portions of faecal homogenate were incubated, the control and one to which the extra carbohydrate contained in the diet was added. In addition, small samples of faecal homogenate from two subjects eating cellulose were 
incubated for a further $12 \mathrm{~d}$, making $14 \mathrm{~d}$ in all, as little digestion seemed to have occurred by $48 \mathrm{~h}$.

\section{Analyses}

Total $\mathbf{N}$ was determined by a micro-Kjeldahl procedure, ammonia by the microdiffusion method of Conway \& Byrne (1936), pH by glass electrode, and osmolality by freezing-point depression with an Advanced Instruments Inc. osmometer. Two methods were used for measurement of SCFA anions: (1) the column extraction-titration procedure of Collin \& McCormick (1974), which gives excellent correlation with gas-liquid chromatographic measurements of individual SCFA in faecal extracts, and is here designated 'total SCFA anions (titration) '; and (2) the gas-liquid chromatographic method of Cochrane (1975), for separate measurements of acetate, propionate and $n$-butyrate, the sum of these concentrations being designated 'total SCFA anions (GLC)'. SCFA anions were measured by titration only in samples from subjects consuming carbohydrates for 7 and $14 \mathrm{~d}$, and in homogenates incubated with added cellulose for $14 \mathrm{~d}$, as these samples were too small for measurement by both methods. Preparation of faecal homogenates for the gas-liquid chromatographic procedure was by a modification of the extraction procedure of Whitehead et al. (1976); samples were first mixed with Analar grade concentrated orthophosphoric acid, $0.2 \mathrm{ml}$ to $1.0 \mathrm{ml}$ of sample, centrifuged at $2250 \mathrm{~g}$ for $20 \mathrm{~min}$ at $4^{\circ}$, and the supernatant fraction then recentrifuged at $46000 \mathrm{~g}$ for $90 \mathrm{~min}$ at $4^{\circ}$. To $1 \mathrm{ml}$ supernatant fraction, $0.1 \mathrm{ml} 3$-methyl valeric acid $(50 \mathrm{mmol} / \mathrm{l})$ was added as an internal standard. To remove volatile amines, samples were brought to $\mathrm{pH} 11$ with sodium hydroxide and then extracted twice with dimethyl ether. Excess hydrochloric acid was added to the aqueous phase, SCFA were extracted twice with dimethyl ether and the extract reduced to $3 \mathrm{ml}$ and dried with anhydrous sodium sulphate before gas-liquid chromatography.

In the Conway ammonia method some difficulty was experienced with samples of faecal incubate from three subjects taking cellulose and in samples from one of these subjects on lactulose and arabinogalactan, caused by creeping of fluid from the outer to the inner chamber of the Conway unit. The difficulty was overcome by decreasing the sample size from 0.2 to $0.1 \mathrm{ml}$ and the period of diffusion from 4 to $2 \mathrm{~h}$, a procedure which still gives over $99 \%$ of recovery of ammonia (Conway \& Byrne, 1936). We have not previously encountered this creeping phenomenon in over 1000 determinations of faecal ammonia, and suspect that it arose from a decrease in the surface tension of samples caused by changes in either the excretion or the bacterial metabolism of bile salts.

Bacterial counts of the five main groups of large-bowel micro-organisms (gram-negative anaerobes, gram-positive anaerobes, enterobacteria, enterococci and lactobacilli) were made as described in detail by Vince et al. (1976).

\section{RESULTS}

\section{Organic anion generation during incubation}

Unsupplemented control incubates. During incubation total organic anion concentrations increased to more than double their initial values, the increment in total SCFA anions (GLC) averaging $43 \mathrm{mmol} / 1$, equivalent to $172 \mathrm{mmol} / \mathrm{kg}$ in the original stool sample; the amount of organic anion generated was not influenced by previous addition of the various carbohydrates to the diet (Table 1).

Supplemented incubates. During the first $48 \mathrm{~h}$ of incubation, incubates which were supplemented with lactulose, pectin and arabinogalactan formed amounts of organic anion which were more than twice those of their non-supplemented paired controls, but the 
Table 1. Total short-chain fatty acid anions measured by gas-liquid chromatography $(\mathrm{mmol} / \mathrm{l})$ in faecal incubation systems before and after addition of dietary carbohydrates $\dagger$

(Mean values and standard deviations)

\begin{tabular}{|c|c|c|c|c|c|c|c|c|c|}
\hline \multirow{3}{*}{$\begin{array}{c}\text { Dietary } \\
\text { addition }\end{array}$} & \multirow{3}{*}{$\begin{array}{c}\text { Faecal } \\
\text { incubate } \\
\text { supplement }\end{array}$} & \multicolumn{4}{|c|}{ Period of incubation (h) } & \multirow{2}{*}{\multicolumn{2}{|c|}{$\begin{array}{l}\text { Mean } \\
\text { increase } \\
(0-48 \mathrm{~h})\end{array}$}} & \multirow{2}{*}{\multicolumn{2}{|c|}{$\begin{array}{l}\text { Increase }(0-48 \mathrm{~h}) \text { in } \\
\text { supplemented over } \\
\text { control incubates }\end{array}$}} \\
\hline & & \multicolumn{2}{|c|}{0} & \multicolumn{2}{|c|}{48} & & & & \\
\hline & & Mean & SD & Mean & SD & Mean & $\mathrm{SD}$ & Mean & SD \\
\hline - & - & \multirow{5}{*}{$19 \cdot 7$} & \multirow{5}{*}{9} & 62 & 34 & 43 & 27 & & \\
\hline - & Lactulose & & & $122^{*}$ & 15 & 103 & 16 & 60 & 30 \\
\hline - & Pectin & & & $121^{*}$ & 25 & 101 & 27 & 58 & 35 \\
\hline - & Arabinogalactan & & & $137^{*}$ & 21 & 117 & 14 & 75 & 14 \\
\hline- & Cellulose & & & 74 & 51 & 54 & 44 & 11.8 & 50 \\
\hline Lactulose & - & \multirow{2}{*}{23} & \multirow{2}{*}{11} & 68 & 30 & 45 & 32 & \multirow{2}{*}{68} & \multirow{2}{*}{17} \\
\hline Lactulose & Lactulose & & & $137^{*}$ & 33 & 114 & 39 & & \\
\hline Pectin & - & \multirow{2}{*}{$16 \cdot 5$} & \multirow{2}{*}{8} & 70 & 26 & 54 & 20 & \multirow{2}{*}{55} & \multirow{2}{*}{15} \\
\hline Pectin & Pectin & & & $126^{*}$ & 19 & 109 & 15 & & \\
\hline Arabinogalactan & - & \multirow[b]{2}{*}{30} & \multirow{2}{*}{13} & | 87 & 39 & 57 & 22 & \multirow{2}{*}{71} & \multirow{2}{*}{14} \\
\hline Arabinogalactan & Arabinogalactan & & & $\left\{158^{*}\right.$ & 39 & 128 & 28 & & \\
\hline Cellulose & - & \multirow{2}{*}{$19 \cdot 0$} & \multirow{2}{*}{6} & $\{60$ & 23 & 41 & 22 & \multirow{2}{*}{0.2} & \\
\hline Cellulose & Cellulose & & & 60 & 16 & 41 & 16 & & \\
\hline
\end{tabular}

Mean values were significantly different from the paired control at $48 \mathrm{~h}$ : ${ }^{*} P<0 \cdot 05$.

$\dagger$ For details, see p. 18 .

quantity of organic anion generated did not differ significantly between these three carbohydrates. The average $48 \mathrm{~h}$ increment in the concentration of total SCFA anions (GLC), over that of control incubates, was $65 \mathrm{mmol} / 1$ (Table 1), a value corresponding to an organic acid yield of $6.5 \mathrm{mmol} / \mathrm{g}$ carbohydrate present, or $1.05 \mathrm{~mol}$ organic acid/mol hexose added if, for the sake of convenience, it is assumed that all three carbohydrates consist entirely of hexose polymers, as in the case of cellulose, with a molecular weight of 162 (Hungate, 1966). When two subjects consumed carbohydrate for $14 \mathrm{~d}$, and their faecal homogenates were incubated for $48 \mathrm{~h}$ with the carbohydrate they had been adding to their diet, there was no increase in organic acid production over that seen after only $2 \mathrm{~d}$ of ingestion, the average concentration of total SCFA anion (titration) being 114, 94, 105 and $90 \%$ of the concentration found after $2 \mathrm{~d}$ of ingestion (values from lactulose, pectin, arabinogalactan and cellulose studies respectively).

Addition of cellulose to faecal incubates caused no greater increment in total organic anion concentration at $48 \mathrm{~h}$ of incubation than was present in their unsupplemented paired control faecal incubates. However, after $14 \mathrm{~d}$ of incubation the faecal incubates containing cellulose from two subjects who had eaten cellulose contained 13.4 and $24.7 \mathrm{mmol} / 1$ more total SCFA (titration) than did their paired unsupplemented control incubates; these two values are equivalent to only 23 and $44 \%$ respectively of the corresponding average $48 \mathrm{~h}$ SCFA increments from faecal incubates containing the other three carbohydrates.

\section{Individual SCFA}

All three SCFA increased markedly during incubation, regardless of the experimental protocol used, but acetate was the major SCFA in all incubates at all times (Table 2). When extra carbohydrate had not been eaten, propionate and $n$-butyrate were present in 
Table 2. Individual short-chain fatty acid anions ( $m m o l / l)$ in faecal incubation systems before and after addition of dietary carbohydrates $\dagger$

(Mean values and standard deviations)

\begin{tabular}{|c|c|c|c|c|c|c|c|c|}
\hline \multirow{2}{*}{$\begin{array}{l}\text { Dietary } \\
\text { addition }\end{array}$} & \multirow{2}{*}{$\begin{array}{l}\text { Faecal incubate } \\
\text { supplement }\end{array}$} & \multirow{2}{*}{$\begin{array}{l}\text { Period of } \\
\text { incubation } \\
\text { (h) }\end{array}$} & \multicolumn{2}{|c|}{ Acetate } & \multicolumn{2}{|c|}{ Propionate } & \multicolumn{2}{|c|}{ Butyrate } \\
\hline & & & Mean & SD & Mean & SD & Mean & SD \\
\hline 一 & - & 0 & 13 & 8 & $3 \cdot 1$ & $1 \cdot 2$ & $3 \cdot 3$ & 1.8 \\
\hline - & - & 48 & 41 & 26 & $10 \cdot 8$ & $2 \cdot 5$ & $10 \cdot 7$ & 6.6 \\
\hline- & Lactulose & 48 & 82 & 16 & 16 & $1 \cdot 3$ & 25 & 8 \\
\hline- & Pectin & 48 & 83 & 23 & 16 & $2 \cdot 1$ & 21 & 5 \\
\hline- & Arabinogalactan & 48 & 83 & 6 & 31 & 7 & 24 & 11 \\
\hline - & Cellulose & 48 & 45 & 31 & 15 & 9 & 14 & 13 \\
\hline Lactulose & - & 0 & 16 & 8 & $2 \cdot 9$ & $0 \cdot 9$ & $4 \cdot 3$ & $2 \cdot 5$ \\
\hline Lactulose & -- & 48 & 39 & 17 & 13 & 6 & 17 & 9 \\
\hline Lactulose & Lactulose & 48 & 85 & 15 & 16 & 9 & 36 & 11 \\
\hline Pectin & - & 0 & 11 & 5 & $2 \cdot 8$ & $1 \cdot 3$ & $3 \cdot 2$ & $2 \cdot 1$ \\
\hline Pectin & - & 48 & 41 & 14 & 14 & 5 & 15 & 9 \\
\hline Pectin & Pectin & 48 & 77 & 5 & 19 & 5 & 30 & 10 \\
\hline Arabinogalactan & - & 0 & 19 & 8 & $4 \cdot 7$ & $1 \cdot 7$ & $6 \cdot 3$ & 3.6 \\
\hline Arabinogalactan & - & 48 & 45 & 18 & 19 & 8 & 24 & 17 \\
\hline Arabinogalactan & Arabinogalactan & 48 & 87 & 15 & 31 & 9 & 40 & 20 \\
\hline Cellulose & - & 0 & 12 & 4 & $3 \cdot 1$ & $1 \cdot 2$ & $3 \cdot 5$ & $1 \cdot 7$ \\
\hline Cellulose & - & 48 & 33 & 12 & 12 & 4 & 16 & 9 \\
\hline Cellulose & Cellulose & 48 & 32 & 8 & 13 & 4 & 16 & 7 \\
\hline
\end{tabular}

$\uparrow$ For details, see p. 18.

approximately equal concentrations at $0 \mathrm{~h}$ and $48 \mathrm{~h}$ in the unsupplemented control incubates, but showed no consistent pattern in supplemented incubates. After carbohydrate had been eaten, butyrate exceeded propionate in all incubates, both unsupplemented and supplemented, at $0 \mathrm{~h}$ and $48 \mathrm{~h}$.

Traces of isobutyrate, valerate, isovalerate and hexanoate (not shown separately) were also found, but collectively constituted less than $5 \%$ of total SCFA; no consistent changes were seen in the composition of these minor components with any experimental protocol.

\section{Ammonia}

The concentration of ammonia increased steadily during incubation in all samples except those supplemented with lactulose, in which it fell before rising (Vince et al. 1978).

Unsupplemented control incubates. Ingestion of extra carbohydrates did not reduce net ammonia generation significantly at any of the individual sampling times, but when $0,1.5$ (not shown separately) and $3 \mathrm{~h}$ results were pooled, significantly less ammonia was generated in incubates from subjects who had eaten lactulose or arabinogalactan $(P<0.01$ and $P<0.05$ respectively); no such effect occurred in incubates from subjects who had eaten pectin or cellulose (Table 3 ).

Supplemented faecal incubates. Before ingestion of extra dietary carbohydrate, lactulose was the only supplement added to faecal incubate that significantly reduced net ammonia generation $(P<0.001$ at $6 \mathrm{~h})$; pectin and arabinogalactan supplements appeared to reduce ammonia concentrations at $3-24 \mathrm{~h}$, but the differences from control values were not significant (Table 3). After dietary additions the faecal incubates supplemented with 
Table 3. Ammonia (mmol/l) in faecal incubation systems before and after addition of dietary carbohydrates $\dagger$

(Mean values and standard deviations)

\begin{tabular}{|c|c|c|c|c|c|c|c|c|c|c|c|}
\hline \multirow{3}{*}{$\begin{array}{l}\text { Dietary } \\
\text { addition }\end{array}$} & \multirow{3}{*}{$\begin{array}{c}\text { Faecal } \\
\text { incubate } \\
\text { supplement }\end{array}$} & \multicolumn{10}{|c|}{ Period of incubation $(h)$} \\
\hline & & \multicolumn{2}{|c|}{0} & \multicolumn{2}{|l|}{3} & \multicolumn{2}{|c|}{6} & \multicolumn{2}{|c|}{24} & \multicolumn{2}{|c|}{48} \\
\hline & & Mean & SD & Mean & SD & Mean & SD & Mean & SD & Mean & SD \\
\hline - & - & \multirow{5}{*}{$7 \cdot 6$} & \multirow{5}{*}{$5 \cdot 9$} & $11 \cdot 8$ & 7 & 17 & 7 & 32 & 14 & 40 & 16 \\
\hline$-\ldots$ & Lactulose & & & $3 \cdot 4^{*}$ & 4 & $5 \cdot 8^{*}$ & 6 & $20^{*}$ & 11 & 29 & 14 \\
\hline .-- & Pectin & & & $9 \cdot 0$ & 8 & $11 \cdot 0$ & 13 & 26 & 16 & 37 & 19 \\
\hline- & Arabinogalactan & & & $10 \cdot 0$ & 8 & $11 \cdot 1$ & 11 & 26 & 13 & 40 & 15 \\
\hline- & Cellulose & & & 11.6 & 8 & 18 & 11 & 29 & 13 & 36 & 13 \\
\hline Lactulose & - & \multirow{2}{*}{$3 \cdot 7$} & \multirow{2}{*}{2.6} & $6 \cdot 2$ & 4 & 8.9 & 5 & 26 & 11 & 38 & 16 \\
\hline Lactulose & Lactulose & & & $2 \cdot 1^{*}$ & 3 & $5 \cdot 1^{*}$ & 5 & 23 & 13 & 38 & 17 \\
\hline Pectin & - & \multirow{2}{*}{$8 \cdot 3$} & \multirow{2}{*}{$4 \cdot 4$} & $\int 16$ & 6 & 21 & 9 & 39 & 17 & 54 & 22 \\
\hline Pectin & Pectin & & & $\left\{10 \cdot 5^{*}\right.$ & 6 & $15^{*}$ & 11 & 38 & 19 & 53 & 22 \\
\hline Arabinogalactan & - & \multirow{2}{*}{$5 \cdot 9$} & \multirow{2}{*}{$5 \cdot 5$} & $\{10 \cdot 9$ & 9 & 16 & 13 & 33 & 21 & 44 & 21 \\
\hline Arabinogalactan & Arabinogalactan & & & $\{5 \cdot 9 *$ & 8 & $8 \cdot 6^{*}$ & 10 & $25^{*}$ & 18 & 38 & 23 \\
\hline Cellulose & - & \multirow{2}{*}{$6 \cdot 8$} & \multirow{2}{*}{$0 \cdot 5$} & $\{14$ & 3 & 18 & 5 & 33 & 11 & 46 & 17 \\
\hline Cellulose & Cellulose & & & 13 & 4 & 19 & 6 & 35 & 10 & 49 & 13 \\
\hline
\end{tabular}

Mean values were significantly different from paired control: ${ }^{*} P<0.05$

$\dagger$ For details, see p. 18.

lactulose, pectin and arabinogalactan all generated significantly less ammonia than their unsupplemented paired controls $(P<0.05$ for all three carbohydrates at $6 \mathrm{~h}$ ). Cellulose did not alter the amounts of ammonia generated in any incubate at any time.

Pectin was the only substrate which on ingestion significantly $(P<0.05$ at $48 \mathrm{~h})$ increased net ammonia generation. These increments were probably due to the increased excretion of faecal $\mathrm{N}$ by subjects consuming pectin, for they were much less when expressed as percentages of total $\mathrm{N}$ converted to ammonia, i.e. $15.3 \%$ of total $\mathrm{N}$ was converted to ammonia in the unsupplemented control before pectin ingestion, and similar values $(16 \cdot 1$ and $16.1 \%$ respectively) were converted in the unsupplemented and pectin-supplemented incubates from subjects eating pectin $(P>0 \cdot 10)$. Pectin increased faecal total $N$ concentration in $0 \mathrm{~h}$ faecal homogenates, from 230 (SD 46) $\mathrm{mmol} / \mathrm{l}$ before ingestion of any carbohydrate, to $304(\mathrm{SD} 58) \mathrm{mmol} / \mathrm{l}(P<0.02)$ in subjects taking pectin; in subjects ingesting other carbohydrates faecal total $\mathrm{N}$ values $(\mathrm{mmol} / \mathrm{l})$ were not significantly different from control values: 204 (SD 66) on lactulose, 205 (SD 68) on arabinogalactan and 211 (SD 39) on cellulose.

Consumption of carbohydrates for $14 \mathrm{~d}$ rather than for $2 \mathrm{~d}$ did not enhance the tendency of faecal incubates to produce lower ammonia concentrations.

\section{$p H$ and osmolality}

At the start of incubation the mean $\mathrm{pH}$ values of each group of faecal homogenates were in the range 6.9-7.0, except when subjects had consumed either lactulose or arabinogalactan, when mean $\mathrm{pH}$ values were $6.4(\mathrm{SD} 0.5$ ) and 6.4 (SD 0.7 ) respectively. Initial osmolality values of the $1: 3(\mathrm{w} / \mathrm{w})$ faecal homogenates in physiological saline (300 mosmol $/ \mathrm{kg}$ ) averaged 317 (SD 19) mosmol $/ \mathrm{kg}$. 
During the $48 \mathrm{~h}$ incubation period the $\mathrm{pH}$ of all samples fell, and osmolality rose, in keeping with the generation of organic acid from carbohydrates. The $\mathrm{pH}$ of incubates supplemented with lactulose, pectin or arabinogalactan dropped rapidly to $5 \cdot 5$, at which point automatic titration with sodium hydroxide contributed to osmolality while maintaining a steady $\mathrm{pH}$. Although this factor complicates further interpretation of osmolality values, calculation showed that an average of at least $37 \mathrm{mosmol} / \mathrm{kg}$ of the $48 \mathrm{~h}$ increase in osmolality of supplemented samples over controls (mean 123 mosmol $/ \mathrm{kg}$ ) could not be attributed to SCFA, ammonia or added sodium hydroxide.

\section{Fate of ingested and incubated carbohydrate}

No lactulose was detected in four faecal samples from two subjects ingesting lactulose. Faecal pectin, arabinogalactan and cellulose were not measured.

\section{Bacteriology}

Effect of diet. The four dietary supplements had no significant effect after either 2 or $14 \mathrm{~d}$ on the faecal counts of total anaerobes, total aerobes, gram-negative anaerobes, grampositive anaerobes, enterobacteria, enterococci or lactobacilli.

Effect of incubation. Organisms survived well during the $48 \mathrm{~h}$ faecal incubation period, with significant falls in only one set of incubates. In the five sets of $0 \mathrm{~h}$ homogenates, obtained both before and during ingestion of extra carbohydrate, mean counts $/ \mathrm{ml}$ (log to the base 10) ranged from $9.4(\mathrm{SD} 0.6$ ) to 9.5 (SD 0.7) for gram-negative anaerobes, from 9.0 (SD 0.6) to 9.5 (SD 0.6) for gram-positive anaerobes, from 5.4 (SD 1.5) to 6.8 (SD 1.1) for enterobacteria, from $5 \cdot 1(\mathrm{SD} 0.5)$ to $6.0(\mathrm{SD} 0.9)$ for enterococci, and from $3 \cdot 5$ (SD 2.7) to $5 \cdot 3$ (SD 1.3) for lactobacilli. After $48 \mathrm{~h}$, mean counts of the five sets of control incubates, and seven of the eight sets to which extra carbohydrate had been added at the start of incubation, ranged from 8.4 (SD 1.0) to 9.3 (SD 0.5) for gram-negative anaerobes, from 8.1 (SD 0.9 ) to 9.4 (SD 0.8) for gram-positive anaerobes, from 4.6 (SD 3.6 ) to 7.0 (SD 0.6 ) for enterobacteria, from 5.5 (SD 1.1) to 6.1 (SD 0.8 ) for enterococci, and from 2.6 (SD 2.3) to 5.3 (SD 0.7) for lactobacilli. In the eighth set of $48 \mathrm{~h}$-supplemented incubates (those containing arabinogalactan from subjects ingesting arabinogalactan) counts of three groups of organisms fell significantly, from 9.5 (SD 0.3) to 8.2 (SD 1.0) for gram-negative anaerobes, from 9.4 (SD 0.2 ) to 7.9 (SD 1.1) for gram-positive anaerobes, and from 6.4 (SD 1.4) to 3.1 (SD 0.8) for enterobacteria; there were no significant changes in the counts of either enterococci, 5.6 (SD 1.0) and 5.5 (SD 0.9), or lactobacilli, 3.5 (SD 2.7) and 4.1 (SD 2.2), at 0 and $48 \mathrm{~h}$ respectively.

\section{DISCUSSION}

Fresh human faeces contain large amounts of SCFA (Rubinstein et al. 1969) which increase further when the faeces are incubated, even without added carbohydrate (Vince et al. 1978). In the present study the mean increase in SCFA on incubation of controls was $43 \mathrm{mmol} / \mathrm{l}$ (Table 1), equivalent to $172 \mathrm{mmol} / \mathrm{kg}$ from the original stool. The nature of the bacterial substrate giving rise to the increment in SCFA is not known but it is likely to represent a number of different substances, including residues of dietary carbohydrates, proteins and fats, and endogenous proteins from intestinal secretions (particularly the carbohydrate component of mucoproteins) and shed epithelial cells.

Of the four carbohydrates added to our faecal incubation system, lactulose, pectin and arabinogalactan were all fermented vigorously, with the production of very similar amounts of SCFA at $48 \mathrm{~h}$ (Table 1). The concentration of lactulose used here is completely metabolized in this incubation system within $6 \mathrm{~h}$ (Vince et al. 1978) so the similar yield of 
SCFA from pectin and arabinogalactan strongly suggests virtually complete fermentation of all three carbohydrates by $48 \mathrm{~h}$. These observations are in agreement with findings of other studies on the digestion of carbohydrates during intestinal transit in man, which have shown total digestion of pectin (Cummings et al. 1979) and 85-100\% digestion of isphagula (Prynne \& Southgate, 1979), an arabinoxylan of similar structure to arabinogalactan.

The mean yield of SCFA from these three carbohydrates was in the range demonstrated by others for in vitro models of bacterial fermentation in the gut. Bowie (1962) and Hungate (1966) found the rumen fluid yielded 5.4-7.2 mmol SCFA/g from glucose, dextrin and cellulose substrates, and recently Englyst et al. (1987) harvested 5.4-8.3 mmol SCFA/g carbohydrate from mixed human intestinal organisms incubated with arabinogalactan, xylan and pectin. However, our mean yield of $6.5 \mathrm{mmol} / \mathrm{g}$ carbohydrate, or $1.05 \mathrm{~mol} / \mathrm{mol}$ hexose equivalent, is appreciably less than the theoretical amounts of $9.6-10.5 \mathrm{mmol} / \mathrm{g}$ carbohydrate derived from stoichiometric calculations by several workers for fermentation in both the rumen and the large intestine (Hungate, 1966; Miller \& Wolin, 1979; Cummings, $1981 b$ ). This discrepancy may be partly explained by the fact that these theoretical calculations were based on the complete fermentation of carbohydrate to SCFA, methane and carbon dioxide only, whereas small amounts of many other carbon compounds (e.g. lactate, succinate, higher fatty acids, methanol and ethanol) are produced, as shown by our own osmolality values where we were unable to account for about $30 \%$ of the increased osmolality in supplemented samples. Furthermore, a substantial proportion of carbon derived from the fermented carbohydrate is incorporated into bacterial protoplasm.

Cellulose, the fourth carbohydrate we tested, produced little SCFA in our incubates. Undoubtedly some forms of cellulose are digested by the human intestinal flora (Cummings, $1981 \mathrm{a}$; Kelleher et al. 1984) but the commercial preparation used in our studies is derived from cotton, which is known to be relatively resistant to bacterial degradation (Halliwell \& Bryant, 1963; Hungate, 1966), although Alexander (1952) found even this form of cellulose to be completely digested in the horse caecum within $48 \mathrm{~h}$.

In our faecal incubation system acetate was the predominant SCFA, with smaller amounts of propionic and $n$-butyric acids, just as occurs in human faeces (Rubinstein et al. 1969) and in the rumen and large intestine of all mammals examined (Elsden et al. 1946; Bugaut, 1987). In most human and animal studies propionate concentrations have been greater than butyrate, though sometimes the reverse has been found (Wrong et al. 1981; Cummings et al. 1987; Bugaut, 1987). In the present study butyrate concentrations usually exceeded those of propionate, especially after addition of fermentable carbohydrate. If similar changes occur in the intact large intestine after ingestion of fermentable carbohydrate, these might be of clinical benefit because butyrate is an important metabolic fuel for colonic epithelial cells (Roediger, 1982), offering possible protection of the mucosa in the presence of intestinal disease (Roediger, 1980). Differences in either the types or proportions of various minor components of organic acid may have caused the loss in bacterial viability observed in incubates to which arabinogalactan was added, for several short-chain organic acids produced by bacteria have shown powerful effects in inhibiting the growth of intestinal bacteria (Hentges, 1970; Rolfe, 1984).

Lactulose, pectin and arabinogalactan each slowed the rate at which ammonia was generated in faecal incubates, although without pre-feeding, significant reductions were obtained with lactulose only. After pre-feeding, significant reductions in ammonia generation occurred in the control incubates from subjects who had eaten lactulose and arabinogalactan (but not pectin), changes which were apparent over the first $3 \mathrm{~h}$ of incubation, and then vanished. Whilst it might appear surprising that ingestion of extra 
carbohydrate for such a short period could alter bacterial metabolism so easily, and that the effect should be reversed so rapidly, it is known that for one colonic bacterium, Bacteroides ovatus, exposure to polysaccharide substrate results in increased activity of degenerative enzymes within $2 \mathrm{~h}$, both in dividing and in non-dividing cells (Salyers, 1979). Pectin and arabinogalactan are normal dietary constituents, being present as structural polysaccharides in plant cell walls, and small amounts of lactulose arise in food by conversion from lactose during heating (Bernhart et al. 1965). Bacteria in the intestine are therefore frequently exposed to these substrates and have developed the ability to induce or inhibit the enzymes required for their metabolism fairly rapidly. The mechanisms by which bacteria alter their enzymic activities have been reviewed recently (Vince, 1986; Wrong, 1988) and will not be discussed further here.

Our results show that lactulose, pectin and arabinogalactan yield similar amounts of SCFA when fermented by intestinal bacteria, suggesting that as dietary supplements they would make similar contributions to total energy requirements (McNeil, 1988). Arabinogalactan might have some value in the treatment of porto-systemic encephalopathy, as it will tend to lower ammonia absorption without the drastic purgation which may attend the use of lactulose. As a dietary supplement pectin increases ammonia generation by faecal incubates, probably because it increases ileo-caecal flow of total $\mathrm{N}$ (Sandberg et al. 1983) and, hence, the colonic substrate available for ammonia generation, so it has no place in the therapy of porto-systemic encephalopathy.

This work was supported by the Medical Research Council. The authors thank Dr I. S. Menzies of St Thomas' Hospital, London, for the analysis of lactulose.

\section{REFERENCES}

Alexander, F. (1952). Some functions of the large intestine of the horse. Quarterly Journal of Experimental Physiology 37, 205-214.

Bernhart, F. W., Gagliardi, E. D., Tomarelli, R. M. \& Stribley, R. C. (1965). Lactulose in modified milk products for infant nutrition. Journal of Dairy Science 48, 399-400.

Bingham, S., Cummings, J. H. \& McNeil, N. I. (1979). Intake and sources of dietary fibre in the British population. American Journal of Clinical Nutrition 32, 1313-1319.

Bowie, W. C. (1962). In vitro studies of rumen microorganisms, using a continuous-flow system. American Journal of Veterinary Research 23, 858-867.

Bugaut, M. (1987). Occurrence, absorption and metabolism of short chain fatty acids in the digestive tract of mammals. Comparative Biochemistry and Physiology 86B, 439-472.

Chadwick, V.S., Vince, A., Killingley, M. \& Wrong, O. M. (1978). The metabolism of tartrate in man and the rat. Clinical Science and Molecular Medicine 54, 273-281.

Cochrane, G. C. (1975). A review of the analysis of free fatty acids. Journal of Chromatographic Science 13, $440-447$.

Collin, D. P. \& McCormick, P. G. (1974). Determination of short-chain fatty acids in stool ultrafiltrate and urine. Clinical Chemistry 20, 1173-1180.

Conway, E. J. \& Byrne, A. (1936). An absorption apparatus for the micro-determination of certain volatile substances. I. The micro-determination of ammonia. Biochemical Journal 27, 419-429.

Crossley, I. R. \& Williams, R. (1984). Progress in the treatment of chronic portasystemic encephalopathy. Gut 25, 8598.

Cummings, J. H. (1981 a). Dietary fibre. British Medical Bulletin 37, 65-70.

Cummings, J. H. (1981 b). Short chain fatty acids in the human colon. Gut 25, 763-779.

Cummings, J. H., Pomare, E. W., Branch, W. J., Naylor, C. P. E. \& MacFarlane, G. T. (1987). Short chain fatty acids in large intestine, portal, hepatic and venous blood. Gut 28, 1221-1227.

Cummings, J. H., Southgate, D. A. T., Branch, W. J., Wiggins, G. S., Houston, H., Jenkins, D. J. A., Jivraj, T. \& Hill, M. J. (1979). The digestion of pectin in the human gut and its effect on calcium absorption and large bowel function. British Journal of Nutrition 71, 477-485.

Elsden, S. R., Hitchcock, M. W. S., Marshall, R. A. \& Phillipson, A. T. (1946). Volatile acid in the digesta of ruminants and other animals. Journal of Experimental Biology 22, 191-202. 
Englyst, H. N., Hay, S. \& MacFarlane, G. T. (1987). Polysaccharide breakdown by mixed populations of human faecal bacteria. FEMS Microbiology Ecology 45, 163-171.

Halliwell, G. \& Bryant, M. P. (1963). The cellulolytic activity of pure strains of bacteria from the rumen of cattle. Journal of General Microbiology 32, 441-448.

Hentges, D. J. (1970). Enteric pathogen-normal flora interactions. American Journal of Clinical Nutrition 23, $1451-1456$.

Hungate, R. E. (1966). The Rumen and its Microbes. New York: Academic Press.

Kelleher, J., Walters, M. P., Srinivasan, T. R., Hart, G., Findlay, J. M. \& Losowsky, M. S. (1984). Degradation of cellulose within the gastrointestinal tract in man. Gut 25, 811-815.

McNeil, N. I. (1988). Nutritional implications of human and mammalian large intestinal function. In World Review of Nutrition and Dietetics, vol. 56, pp. 1-42 [G. H. Bourne, editor]. Basel: Karger.

McNeil, N. I., Cummings, J. H. \& James, W. P. T. (1978). Short chain fatty acid absorption by the human large intestine. Gut 19, 819-822.

Miller, T. L. \& Wolin, M. J. (1979). Fermentations by saccharolytic intestinal bacteria. American Journal of Clinical Nutrition 32, 164-172.

Prynne, C. J. \& Southgate, D. A. T. (1979). The effects of a supplement of dietary fibre on faecal excretion by human subjects. British Journal of Nutrition 41, 495-503.

Roediger, W. E. W. (1980). The colonic epithelium in ulcerative colitis: an energy-deficiency disease? Lancet ii, $712-715$

Roediger, W. E. W. (1982). Utilization of nutrients by isolated epithelial cells of the rat colon. Gastroenterology 83, 424-429.

Rolfe, R. D. (1984). Interactions among microorganisms of the indigenous intestinal flora and their influence on the host. Reviews of Infectious Disease 6, S73-S79.

Rubinstein, R., Howard, A. V. \& Wrong, O. M. (1969). In-vivo dialysis of faeces as a method of stool analysis. IV. The organic anion component. Clinical Science 37, 549-564.

Salyers, A. A. (1979). Energy sources of major intestinal fermentative anaerobes. American Journal of Clinical Nutrition 32, 158-163.

Sandberg, A. S., Ahderinne, R., Andersson, H., Hallgren, B. \& Hulten L. (1983). The effect of citrus pectin on the absorption of nutrients in the small intestine. Human Nutrition: Clinical Nutrition 37C, 17I-183.

Vince, A. J. (1986). Metabolism of ammonia, urea, and amino acids, and their significance in liver disease. In Microbial Metabolism in the Digestive Tract, pp. 83-105, [M. J. Hill, editor]. Boca Raton, FL.: CRC Press.

Vince, A. \& Burridge, S. M. (1980). Ammonia production by intestinal bacteria: the effects of lactose, lactulose and glucose. Journal of Medical Microbiology 13, 177-191.

Vince, A., Dawson, A. M., Park, N. \& O'Grady, F. W. (1973). Ammonia production by intestinal bacteria. Gut 14, 171-177.

Vince, A., Down, P. J., Murison, J., Twigg, F. J. \& Wrong, O. M. (1976). Generation of ammonia from non-urea sources in a faecal incubation system. Clinical Science and Molecular Medicine 51, 313-322.

Vince, A., Killingley, M. \& Wrong, O. M. (1978). Effect of lactulose on ammonia production in a fecal incubation system. Gastroenterology 74, 544-549.

Weber, F. L. (1981). The use of lactulose in the treatment of portal-systemic encephalopathy. In Nutritional Pharmacology pp. 217-253 [G. A. Spiller, editor]. New York: Alan R. Liss.

Whitehead, J. S., Kim, J. S. \& Prizont, R. (1976). A simple quantitative method to determine short chain fatty acid levels in biological fluids. Clinica Chimica Acta 72, 315-318.

Wrong, O. M. (1988). Bacterial metabolism of protein and endogenous nitrogen compounds. In The Role of the Gut Flora in Toxicity and Cancer pp. 227-262 [I. R. Rowland, editor]. London: Academic Press.

Wrong, O. M., Edmonds, C. J. \& Chadwick, V. S. (1981). The Large Intestine: Its Role in Mammalian Nutrition and Homeostasis, p. 114. Lancaster: MTP Press Ltd. 